\title{
HAT veertig jaar — 'n persoonlike oorsig
}

F.F. Odendal, Emeritus professor in die Afrikaanse en Nederlandse

Taalkunde, Voormalige Randse Afrikaanse Universiteit, Johannesburg, Republiek van Suid-Afrika

Opsomming: In 2005 was dit 40 jaar sedert die verskyning van die eerste uitgawe van HAT (Verklarende Handwoordeboek van die Afrikaanse Taal), onder redakteurskap van P.C. Schoonees, C.J. Swanepoel, S.J. du Toit en C.M. Booysen. Die ontwikkeling voor hierdie publikasie en daarna van HAT 2 en 3 onder die alleenredakteurskap van F.F. Odendal en van HAT 4 en 5 onder die gesamentlike redakteurskap van Odendal en R.H. Gouws, word oorsigtelik geskets.

Sleutelwoorde: HAT (VERKLARENDE HANDWOORDEBOEK VAN DIE AFRIKAANSE TAAL), WAT (WOORDEBOEK VAN DIE AFRIKAANSE TAAL)

\begin{abstract}
HAT Forty Years - A Personal Survey. In 2005 it has been 40 years since the publication of the first edition of HAT (Verklarende Handwoordeboek van die Afrikaanse Taal), then with P.C. Schoonees, C.J. Swanepoel, S.J. du Toit and C.M. Booysen as editors. The development before this publication and subsequently of HAT 2 and 3 under the sole editorship of F.F. Odendal and of HAT 4 and 5 under the combined editorship of Odendal and R.H. Gouws is synoptically sketched.
\end{abstract}

Keywords: HAT (VERKLARENDE HANDWOORDEBOEK VAN DIE AFRIKAANSE TAAL), WAT (WOORDEBOEK VAN DIE AFRIKAANSE TAAL)

1.1 Die verskyning van die vyfde uitgawe van HAT (Verklarende Handwoordeboek van die Afrikaanse Taal) in September 2005, veertig jaar na die publikasie van HAT 1 (1965), en die gelyktydige uittrede van Odendal as lid van die redaksie (waaraan hy verbonde was vanaf 1971), is waarskynlik 'n baie geleë tyd om die hooftrekke van die ontstaan en ontwikkeling van HAT op skrif te stel, ook omdat Odendal die enigste nog lewende redakteur is wat 'n oorsig oor die hele tydperk kan gee, al is daar o.a. weens wisseling van uitgewers, besonderhede waaroor hy nie beskik nie.

1.2 Om die geskiedenis van HAT, veral wat sy ontstaan en die eerste uitgawe te verstaan, is dit nodig om aandag te gee aan die verhouding tussen HAT en die WAT (Woordeboek van die Afrikaanse Taal, aanvanklik slegs bekend as Die Afrikaanse Woordeboek). Dit is algemeen bekend dat daar voor en gedurende die jare twintig van die vorige eeu ernstige gesprekke deur kundiges gevoer is oor die totstandbrenging van 'n Afrikaanse woordeboek. (Daar is in 
een stadium selfs ' $n$ tweetalige woordeboek oorweeg.) Uiteindelik is 'n mate van vastigheid bereik toe ' $n$ ooreenkoms in Maart 1926 aangegaan is tussen die Nasionale Pers en die regering om 'n eentalige verklarende woordeboek van ongeveer die omvang van die destydse Nederlandse Van Dale tot stand te bring. Hierdie Van Dale was slegs 'n eendelige werk - eintlik 'n handwoordeboek. J.J. Smith, professor in Afrikaans aan die Universiteit van Stellenbosch, sou die redakteur wees, en die werk moes binne drie jaar voltooi word. Die gestelde tydperk was, agterna gesien, heeltemal onrealisties; dit toon egter ook hoe dringend die taak beskou is. Toe die woordeboek nie binne die voorgestelde tyd voltooi is nie, het die Universiteit van Stellenbosch die Nasionale Pers se deel van die kontrak oorgeneem; nou sou die woordeboek binne vyf jaar voltooi moes word (ewe onrealisties as die eerste doelwit).

1.3 Prof. Smith het na ongeveer 20 jaar om gesondheidsredes verlof geneem en nie verder aan die woordeboek gewerk nie. In 1947 is hy deur dr. P.C. Schoonees (skoolhoof op Vryheid) as hoofredakteur opgevolg. Sonder om in besonderhede te tree, moet vermeld word dat die doelwit van die WAT drasties verskuif het. $\mathrm{Na}$ 'n Kommissie van Ondersoek aanbevelings gemaak het, is o.m. ' $n$ Raad van Beheer ingestel, wat die WAT-onderneming op 'n vaster basis geplaas het. Die Sekretaris van Onderwys sou as voorsitter dien en die Rektor van die Universiteit van Stellenbosch as administrateur. Belangrik was dat die doelwit van die WAT nou was om 'n omvattende werk te lewer wat die "volledige" Afrikaanse woordeskat sou opteken en verklaar, met as voorbeelde die OED (The Oxford English Dictionary) en die WNT (Woordenboek der Nederlandsche Taal). Só 'n werk kon bepaald nie binne vyf jaar voltooi word nie.

1.4 Onder Schoonees se deurdrywende leiding het die eerste deel (A-C) in 1951 die lig gesien, die tweede (D-F) in 1955 en deel III (G) in 1957. Dit was nou duidelik dat die Woordeboek, anders as in die eerste 20 jaar, konstante vordering sou maak - en hiervoor verdien Schoonees die nodige lof. Dit was eweneens duidelik dat, ten spyte van 'n behoorlike uitbreiding van die redaksie, die Woordeboek nie binne enkele jare voltooi sou word nie. Daarom het die Beheerraad teen die einde van die jare vyftig, begin van die jare sestig, besluit dat gelyklopend met die omvattende werk ook 'n "handwoordeboek", "standaardwoordeboek", "lessenaarwoordeboek", of watter naam dit ook sou kry, aangepak moes word. Advertensies vir 'n redakteur is geplaas (volgens beplanning sou dit ' $n$ eenpersoonstaak wees), talle aansoeke is ontvang en ' $n$ tweetal kandidate is as aanstelbaar beskou, t.w. drr. M.J. Posthumus en L.R. Heiberg (mondelinge medeling van Schoonees aan Odendal). Die Beheerraad het egter van hierdie besluit afgesien en geen aanstelling is gemaak nie.

Dit is onnodig om hier in verdere besonderhede oor die vordering van die WAT te tree, daar dit HAT weinig geraak het, en volledig uiteengesit is deur Schoonees (s.j.), Snijman (1975²) en Gericke (1991). 
2.1 Die gesprek en onderhandelinge rondom ' $n$ handwoordeboek by die WAT het wel 'n baie positiewe resultaat gehad: Schoonees het naamlik die idee opgevat om in sy eie tyd so 'n werk op te stel. Die Beheerraad het sy voorneme goedgekeur, selfs met soveel entoesiasme dat hy toestemming verkry het om die materiaal van die WAT te gebruik. So het 'n noue band ontstaan tussen die WAT en die eerste uitgawe van HAT. Nadat Schoonees oorlede is, het HAT nie verder hierdie band behou nie.

2.2 Schoonees het met sy gebruiklike geesdrif, werkkrag en deursettingsvermoë begin werk aan HAT. Dit het egter gou geblyk dat dit 'n moeilike, selfs onmoontlike taak vir een persoon was om in ' $n$ kort tyd te voltooi. Schoonees het Odendal reeds vroeg genader om op gelyke voet met hom saam te werk, 'n aanbod wat Odendal om diverse redes van die hand gewys het. Hy het egter die naam van C.J. Swanepoel, lid van die redaksie van die WAT, aan Schoonees genoem. Schoonees het die wenk aanvaar en Swanepoel het positief gereageer. Ook met die hulp van Swanepoel het die werk nie vinnig genoeg na Schoonees se oordeel gevorder nie, en is dr. S.J. du Toit, ook lid van die redaksie van die WAT, as derde redakteur bygebring. Nog later het C. Murray Booysen tot die redaksie van HAT toegetree. Swanepoel was Afrikaans-onderwyser voordat hy by die WAT aangesluit het, Du Toit was reeds afgetree, maar voor sy aanstelling as lid van die redaksie van die WAT, hoofinspekteur van die destydse Oranje-Vrystaat, en Booysen was voor sy aftrede op Stellenbosch Direkteur van Onderwys in die destydse Natal.

2.3 Die eerste uitgawe van HAT het in 1965 verskyn onder al vier name in 2.2. genoem, alhoewel Booysen hom reeds om gesondheidsredes aan praktiese deelname onttrek het. Al was hy dit in feite, word Schoonees nie as hoofredakteur aangedui nie. Die uitgewer van HAT 1 was Voortrekkerpers, wat enkele jare later met Afrikaanse Pers Boekhandel saamsmelt om Perskor te vorm, die firma wat HAT 2-HAT 4 uitgegee het (al het Perskor reeds voor die verskyning van HAT 4 opgegaan in Maskew Miller Longman (MML)). HAT 5 is uitgegee deur Pearson Education South Africa (PESA), die afdeling van MML wat opvoedkundige werke hanteer.

3. In die "Woord Vooraf" van HAT 1 word, histories gesien, ' $n$ waardevolle uiteensetting gegee van watter dele van die oorspronklike manuskrip deur watter redakteur bewerk is. Dit gee ook 'n indruk van hoe sekere letters verdeel en onderverdeel is onder die verskillende redakteurs in ' $n$ poging om die projek so spoedig moontlik te voltooi. Gaan 'n mens die verdeling van die manuskrip in terme van gedrukte bladsye na, klop die tantième van die verskillende redakteurs nogal goed met die hoeveelheid wat elkeen gelewer het. Die finale verdeling was: P.C. Schoonees 9,92\%, C.J. Swanepoel 4,11\%, S.J. du Toit 3,17\% en C.M. Booysen 2,8\%. 
4.1 Toe Perskor Odendal in 1971 nader met die versoek om die redakteurskap van HAT oor te neem (die oorspronklike redakteurs was oorlede of, indien nog in die lewe, in Perskor se woorde, "te oud" om die werk voort te sit), het dit as ' $n$ totale verrassing gekom. Nie alleen was sy tyd behoorlik in beslag geneem as professor in Afrikaanse en Nederlandse Taalkunde by die jong Randse Afrikaanse Universiteit, as voorsitter van die Taalkommissie van die S.A. Akademie vir Wetenskap en Kuns, eweneens as voorsitter van die Linguistevereniging van Suider-Afrika en ook as lid van die Komitee vir Taaladvies van die SAUK nie, maar hy het lank geen kontak op enige wyse met HAT gehad nie. Hy het, ten spyte van al sy ander bedrywighede, besluit om die aanbod te aanvaar. Sy eerste oorweging was nie 'n finansiële nie, maar die gedagte dat, as alles voorspoedig met HAT verloop, hy na sy aftrede iets sinvols sou hê om te doen. Dit het dan ook so uitgewerk: hy kon tot sy 79ste jaar met HAT besig wees.

Alhoewel Odendal in hierdie stadium slegs enkele artikels oor die leksikografie laat verskyn het, was hy tog nie volkome onkundig op hierdie gebied nie: hy het drie jaar ondervinding by die Vaktaalburo gehad en tien jaar as mederedakteur en assistenthoofredakteur van die WAT; sy jarelange verbintenis (sedert 1962) met die Taalkommissie het hom ook sydelings met die praktyk van werk-met-woorde in verbinding gehou.

By sy aanvaarding van Perskor se aanbod, het Odendal die firma gevra wat hulle as 'n realistiese tyd vir die voltooing van die werk beskou. Die antwoord was twee jaar. Odendal het dit onaanvaarbaar gevind want, soos hy dit gestel het, "ek kan nie my naam teken by 'n werk wat ek nie met 'n mate van deeglikheid beskou en desnoods gewysig het nie". Sy skatting van vier jaar is deur Perskor aanvaar; uiteindelik sou dit agt jaar duur. Die ooreenkoms tussen Perskor en Odendal is in 1972 onderteken.

4.2 Odendal het in 1972 'n volle jaar langverlof gehad en kon dus heelwat tyd aan die herbewerking van HAT afstaan. Sy werkwyse was om die galeiproewe van HAT 1 as basis te gebruik en daarop te wysig, aan te vul en te skrap soos nodig.

Een of twee van die oorspronklike redakteurs het sporadies wysigings en byvoegings aangebring. Die wyse waarop hierdie insette egter voorgelê is, was van so 'n aard dat dit 'n oponthoud eerder as 'n hulp was. Odendal het dus vroeg besluit om hierdie opmerkings te negeer. Gevolglik moet hy die volle verantwoordelikheid vir HAT 2 dra.

5.1 'n Nuwe hoofstuk in die geskiedenis van HAT begin dus in 1972, met Odendal as alleenredakteur vir ongeveer 'n kwarteeu.

Die galeie van HAT 1 het 'n uitbreiding van ongeveer $50 \%$ ondergaan en daar is gepoog om 'n werklik hersiene uitgawe daar te stel: naas byvoegings is definisies gewysig, argaïese woorde (en betekenisse) geskrap, veral ook woorde en betekenisse wat eerder Nederlands as Afrikaans was, alhoewel in hierdie geval omsigtig te werk gegaan is, veral met die oog op ouer taalgebruikers. 
Hier moet die onskatbare bydrae van mev. Estelle Odendal vermeld word, wat dwarsdeur die tyd wat haar man met HAT besig was, op ' $n$ konstante basis nuwe en ontbrekende woorde uit koerante, tydskrifte en boeke opgeteken het. Alhoewel hierdie bydrae telkens in die voorwoord van nuwe uitgawes erken word, is eers in die voorwerk van HAT 5 'n spesiale dankwoord aan haar gerig.

5.2 Een aspek waaraan Odendal by die bewerking van HAT 2 spesiaal aandag gegee het, was die uitbreiding en verbetering van voorbeeldsinne. Dit was, en is, sy oortuiging dat woorde "in aksie" in goed gekose voorbeeldsinne, dus binne sintaktiese verband, hul betekenis(se) duidelik(er) laat blyk as net in 'n (afstandige,) koue, wetenskaplike definisie.

5.3 HAT 2 verskil so ingrypend van HAT 1 dat dit 'n verlies is dat die galeie waarop HAT 2 bewerk is, verlore gegaan het.

5.4 HAT 2 het in 1979 verskyn, onder die name van Odendal plus die oorspronklike vier redakteurs (al het hulle geen bydrae meer gelewer nie). Die bekendstelling het by wyse van 'n geleentheid by die destydse Randse Afrikaanse Universiteit (RAU) geskied, waarby die destydse voorsitter van die Akademie, dr. H.W. Snyman, voorheen voorsitter van die S.A. Mediese Vereniging, ' $n$ leergebonde eksemplaar aan die redakteur oorhandig het. Ook teenwoordig was senior kollegas van die RAU, o.a. die Rektor, prof. J.P. de Lange en ook mnr. C.J. Engelbrecht, bekende taaladviseur by Die Transvaler en verwante publikasies, wat lang lyste voorstelle aan Schoonees en later ook Odendal laat toekom het.

5.5 Toe dit bekend word dat Odendal HAT sou herbewerk, het talle kollegas en lede van die publiek (die meeste van lg. onbekendes) voorstelle tot verbetering en vreemde woorde vir opname aan die uitgewers gestuur. Die grootste deel van hierdie voorstelle was waardevol, en dit was 'n voorreg om sommige bydraers in die voorwoord te bedank.

Werk aan HAT 2 was 'n intrigerende oefening, o.a. omdat HAT 1 so ongelyk van gehalte was vanweë die bewerking deur verskillende redakteurs met verskillende benaderings.

5.6 HAT 2 is baie gunstig deur die pers, radio en televisie ontvang. Odendal het op uitnodiging onderhoude gevoer met verskeie koerante en meermale oor die radio; hy het selfs opgetree in 'n populêre televisieprogram wat hoofsaaklik oor die kunste gehandel het.

6. Intussen het Odendal voortgegaan met werk aan HAT met die oog op 'n derde uitgawe. Dit het spoedig geblyk dat HAT die mark in sy bepaalde nis verower het en as gesaghebbend aanvaar is deur die publiek (oud en jonk). Dit het ' $n$ plek gekry in die meeste skole, asook in regeringskantore, by sakelui, e.d. 
Van besondere belang was dat dit as outoriteit aanvaar is by die bepaling van die betekenis van ' $n$ woord in hoër en laer howe (soos mondeling aan Odendal berig deur 'n regter van die Hoërhof in Transvaal). Voeg hierby dat koerante en briefskrywers aan koerante gereeld HAT as gesaghebbende bron aangehaal het as dit oor die betekenis van 'n woord gaan en dit was duidelik dat HAT geleidelik 'n huishoudelike naam geword het.

7.1 Toe Perskor ernstig begin praat oor 'n derde uitgawe, het Odendal prakties voltyds daaraan begin werk. Hy het selfs in 1989, twee jaar voor sy verpligte aftreedatum, die diens van die Universiteit verlaat om HAT te voltooi. Dat HAT 3 eers in 1994 verskyn het, is objektief beskou nie aan die outeur te wyte nie. Die verskyning van HAT 3 is met twee, drie jaar vertraag deur die uitgewer self. Wat ook al die redes daarvoor, die outeur was en is daar nog steeds onbewus van. Een moontlike rede kon wees dat Perskor reeds finansiële probleme ondervind het, wat die uitgawe van 'n lywige, moeilik setbare werk soos HAT problematies gemaak het.

Daarbenewens kon Odendal nie 'n ooreenkoms vir HAT 3 van Perskor kry nie. Daar was geen nuwe ooreenkoms nodig nie, hoogstens ' $n$ aanpassing van tantièmes. Perskor het egter 'n addendum by die ooreenkoms van HAT 2 verkies, maar ook dit het nie gerealiseer nie. Uiteindelik moes Odendal sterk aandring by die verantwoordelike persoon (nie 'n lid van Perskor se personeel nie) wat die ooreenkoms moes voorberei, om dit te finaliseer.

7.2 Positiewer was die feit dat HAT 3 besonder goed deur die media ontvang is, selfs gunstiger as HAT 2, en Odendal het weer onderhoude met al die media gevoer.

7.3 By die voorbereiding van HAT 3 het Odendal probeer verbeter op al die fasette wat t.o.v. HAT 2 genoem is (vgl. 5.1 en 5.2 hierbo). Die omvang is met $30 \%$ vergroot (moontlik gemaak deur die werk in drie i.p.v. twee kolomme te druk). Argaïese woorde is weer met versigtigheid verwyder. In die besonder is, meer as vroeër, op 'n sistematiese wyse aandag gegee aan etikette, wat eintlik daarop neerkom dat 'n woord sonder etiket, gewone Standaardafrikaans is - in beginsel altans. In die voorwerk word 'n spesiale afdeling afgestaan aan "Gebruiklikste etikette en afkortings". Dat die aanbieding enigsins onsistematies geword het, moet vir die rekening van die uitgewer staan, want dit is nooit aan die redakteur voorgelê nie.

Problematies t.o.v. etikette was veral die "rassistiese" woorde, en in 'n mindere mate wat vandag as "gender"-woorde bekend staan. Daar was sterk druk, ook buite HAT om, om hierdie woorde heeltemal weg te laat om sodoende geen gebruiker van Afrikaans te na te kom nie. Odendal het hom op die standpunt gestel dat dergelike woorde wel opgeneem moet word as 'n volledige beeld van die Afrikaanse woordeskat gegee wil word. Hierdie kategorie woorde moet egter met veel groter omsigtigheid en empatie as in die verlede ge- 
hanteer word. Die juiste etikette (en desnoods nog die bewoording van die definisies self, asook selfs 'n sterk afwysing van die gebruik daarvan) behoort die status van die woorde genoegsaam aan te dui.

7.4 Die waarde wat Odendal aan voorbeeldsinne heg, is vroeër reeds onder 5.2 beklemtoon. In HAT 3 het hy verder gegaan. Nie alleen is sy selfgemaakte voorbeelde vermeerder nie, maar hulle is aangevul met 'n groot aantal sitate uit die werke van Afrikaanse skrywers. Hierdie gebruik is algemeen in woordeboeke van groter omvang, maar rondom 1990 was HAT by die skrywer se wete die enigste woordeboek van sy grootte wat uitgebreid uit die literatuur aangehaal het - en dit geld nie net vir Afrikaans nie. Odendal het sy werkwyse in die voorwoord tot HAT 3 "verdedig" deur daarop te wys dat sitate uit skrywers bewys dat gewone én ongewone woorde ook in die skryftaal van erkende skrywers voorkom. Daardeur word verder erkenning gegee aan die belangrike rol wat die hoë gehalte van ons letterkunde in die bestaansreg van Afrikaans speel.

7.5 Soos in die vorige uitgawes is besonder aandag aan uitdrukkings gegee, is hulle uitgelig en volgens 'n vasgestelde wyse telkens aan die einde van 'n lemma gegroepeer.

7.6 HAT 3 was die eerste Afrikaanse woordeboek wat geprobeer het om 'n behoorlike uiteensetting te gee van sy werkwyse en die teoretiese beginsels waarop dit berus. Oor die lys etikette is reeds onder 7.3 uitgewy. Wat ontbreek het, was ' $n$ skematiese voorstelling waaruit die verskillende afdelings van ' $n$ lemma duidelik blyk, iets wat tot groot hulp vir die gebruiker kan dien. Dit is in die 4 de en nog beter in die 5 de uitgawes reggestel.

8.1 Samewerking tussen Odendal en Perskor t.o.v. HAT 2 en 3 was in die geheel aangenaam. Daar is weinig druk op die redakteur geplaas en voorstelle van sy kant is steeds met groot simpatie bejeën. Minder aangenaam was veral die feit dat die skakelpersoon (eintlik redakteur) by Perskor dikwels vervang is (sonder om Odendal in kennis te stel), wat kommunikasie bemoeilik het; en dat Perskor gereeld toegelaat het dat HAT 2 uit druk was (weer sonder kennisgewing). Ewe lastig was die feit dat Odendal nie altyd op hoogte was met watter firma hy besig was om te werk nie: Perskor, Educum, Kagiso, weer Perskor, weer Educum en so voort. Odendal het eers laat uitgevind dat Perskor oorgeneem is deur Maskew Miller Longman (en dat HAT nie in die slag gebly het nie).

8.2 Die bekendstelling van HAT 3 was teleurstellend. Odendal het by Perskor aangedring dat dit tyd was om HAT 3 bekend te stel: die boek was gedruk en gebind met genoegsame eksemplare om die mark te betree, maar daar was geen responsie van Perskor se kant nie. Uiteindelik is hy in kennis gestel dat daar een middag om drie-uur ' $n$ funksie sou wees in die Doornfontein-kantore 
van Perskor en dat 'n minimum gaste genooi kon word. Dit was 'n geleentheid waarby slegs sowat twaalf persone teenwoordig was en 'n koppie tee bedien is. Die volgende dag het 'n foto van Odendal, saam met die Besturende Direkteur van Perskor, met 'n onderskrif, in Beeld verskyn - en dit was die totale reklame vir HAT 3! Die luukse eksemplaar wat hom by herhaling beloof is, het die redakteur nooit bereik nie.

9. Gedurende die jare neëntig het Odendal Perskor genader met die suggestie dat dit tyd was om 'n tweede, jonger redakteur aan te stel met die oog op 'n vierde en verdere uitgawes. Odendal wou verseker dat HAT in bekwame hande sou wees wanneer hy nie langer kon meewerk nie. Hy het net een naam voorgelê, dié van Rufus H. Gouws (tans professor in die Departement van Afrikaans en Nederlands aan die Universiteit van Stellenbosch). Sy status as teoretiese en praktiese leksikograaf maak hom 'n onbetwiste leier as woordeboekkundige. Sy boek Leksikografie het in 1991 die Suider-Afrikaanse Linguistevereniging se Toekenning vir Taalwetenskap ontvang en sy publikasies sluit hoofstukke in boeke en artikels in al die gesaghebbende vaktydskrifte nasionaal en internasionaal in. Hy was in 1986 en 1992 erenavorsingsgenoot aan die Navorsingsentrum van die Universiteit van Exeter en in 1999 gasprofessor aan die Universiteit van Heidelberg. Hy is mederedakteur van verskeie woordeboeke en het kontakte met talle woordeboekinstansies oorsee, o.a. as hoofredaksielid van De Gruyter se internasionale vakwoordeboek in leksikografie en woordeboeknavorsing. Hy is betrokke by meerdere projekte met kollegas in België en Nederland en lid van nasionale en internasionale verenigings. Hy was o.a. voorsitter van AFRILEX (the African Association for Lexicography). Intussen styg sy aansien hier en in die buiteland en gee hy leiding aan 'n verbasende aantal nagraadse studente, veral in die metaleksikografie.

Dit is moeilik om aan 'n geskikter kandidaat as mederedakteur te dink. Gelukkig was sowel Perskor as Gouws bereid om Odendal se voorstel te aanvaar. Ten spyte van die groot verskil in ouderdom (byna 30 jaar) tussen die twee redakteurs, was die samewerking tussen Gouws en Odendal uiters aangenaam.

10. Voordat voortgegaan word met HAT se publikasie deur Maskew, Miller, Longman (MML) moet aandag gegee word aan 'n uitbreiding t.o.v. HAT, nl. die uitgawe in die jare negentig van 'n elektroniese weergawe van HAT 3 op CD-ROM. Hierdie taak is hoofsaaklik aangepak en deurgevoer deur Gouws en die eer van die peil daarvan plus die toegevoegde waarde op verskeie gebiede, moet hom toekom. Dat daar allerlei probleme opgeduik het, was te verwagte; die ernstigste vertraging was te wyte aan die finalisering van 'n kontrak met Next Page (vroeër Folio Views). Gouws het egter deurgedruk en uiteindelik kon ELHAT (soos die elektroniese HAT gou algemeen bekend geword het) op twee agtereenvolgende aande in Oktober 1998 in 'n restaurant in Kaapstad bekend gestel word. Tans word gewerk aan 'n nuwe uitgawe van ELHAT, nou gebaseer op HAT 5. 
11.1 By die beplanning van HAT 4 het Gouws en Odendal besluit dat die toegelate tyd ' $n$ indringende hersiening van HAT 3 onmoontlik maak en dat, wat die algemene hersiening betref, die alfabet in twee gelyke dele tussen die outeurs verdeel sou word. Odendal sou die eerste, Gouws die tweede gedeelte vir hul rekening neem. Bepaalde aspekte sou egter deur een outeur vir $\mathrm{A}-\mathrm{Z}$ bewerk word, bv. die byvoeging van sitate, verfyning van etikette, en kontrole en aanvulling van rekenaarterme. Ten spyte van die tydsbeperking is talle nuwe woorde bygevoeg en argaïsmes geskrap. 'n Nuutjie was wel (hopelik met die nodige omsigtigheid) die opname van 'n aantal Engelse woorde soos cool, sorry, show en song. Alhoewel hierdie woorde tot 'n minimum beperk is, het dit, soos te verwagte, kritiek uitgelok (tog minder as wat die outeurs voorsien het). Gelukkig was daar ook ondersteuning vir dié "moedige stap" van die redakteurs. 'n Diagram wat die uiteensetting van artikels illustreer, is as deel van die voorwerk bygevoeg.

11.2 Die samewerking tussen die redakteurs het vlot verloop, daar is flink gevorder met die herbewerking van die nuwe deel en HAT 4 kon in November 2000 bekend gestel word by 'n funksie by Oude Libertas, met mnre. Japie Pienaar as seremoniemeester en M.B. Kumalo as geleentheidspreker.

Weer is ' $n$ uitgawe van HAT goed ontvang, maar met minder fanfare as bv. HAT 3. Alhoewel HAT 4 nog onder die imprimatuur van Perskor verskyn het, was dit reeds volledig onder beheer van MML.

12.1 In 2003 versoek Pearson Education South Africa (PESA), wat nou namens MML die uitgewers van HAT was, ietwat onverwags dat die outeurs ' $n$ vyfde uitgawe van HAT in 2004 moet lewer. Albei redakteurs reageer redelik afwysend hierop: dit het net té min tyd toegelaat. Gouws het met die goeie idee gekom dat 2005 nie net 'n realistieser datum sou wees nie, maar dat dit met ' $n$ veertigste verjaarsdagviering van die verskyning van HAT 1 in 1965 gekombineer kon word. PESA het hierdie voorstel aanvaar.

12.2 Wat betref die bewerking van HAT 5 het die redakteurs besluit om elk weer ' $n$ helfte van die werk vir sy spesifieke verantwoordelikheid te neem, dié keer net die omgekeerde as by HAT 4: Gouws die eerste deel, Odendal die tweede. Soos by HAT 4 het elke redakteur spesiale verantwoordelikheid vir bepaalde aspekte van die werk vir die volledige woordeboek aanvaar: uitbreiding van die etimologieë, 'n verbeterde artikeluitleg, uitbreidings van afkortings en verskuiwing van afkortings as 'n eenheid na die einde van die boek, byvoeging van 'n afdeling geografiese name met hulle afleidings, verdere verfyning van etikette, sorg vir ooreenstemming tussen 'n nuwe Afrikaanse Woordelys en Spelreëls en HAT 5, 'n voorteks met volledige gebruikershandleiding, verdere aandag aan geskikte sitate (nie net uit die "bekendste" skrywers nie), en 'n woordkeuse gebaseer op 'n verteenwoordigende, uitgebreide en gebalanseerde elektroniese korpus (waarvoor prof. D.J. Prinsloo van die Universiteit 
van Pretoria dank verdien). Verder is nóg "vreemde", maar gebruiklike woorde opgeneem en met omsigtigheid woorde uit ander variëteite as Standaardafrikaans.

12.3 HAT 5 het betyds van die drukker gekom, in 'n besonder aantreklike maroen band met goue letters en met 'n veel aantrekliker en lesersvriendelike bladspieël plus, vir die eerste keer, duimdrukke, en op veel beter papier gedruk as sy voorganger.

12.4 HAT 5 is op 14 September 2005 by die landgoed Spier bekend gestel, met Laetitia Botha van PESA as seremoniemeester en prof. W.T. Claassen van die Universiteit van Stellenbosch as geleentheidspreker. Elk van die redakteurs het 'n luukse eksemplaar in halfleer gebind, ontvang. Odendal sou reeds na die vierde uitgawe uit die redaksie tree, maar het om verskeie redes aangebly tot die voltooiing van HAT 5. Dit was dus ook 'n afskeid vir hom, na 'n verbintenis van meer as 30 jaar. Tot sy verbasing het PESA dit ook 'n huldiging van hom gemaak, met o.a. 'n waarderingswoord deur Gouws en 'n plaket vir " 'n besondere bydrae tot die leksikografiepraktyk".

13.1 HAT 5 het sekerlik die beste blootstelling van al die uitgawes gehad. Nie alleen het enkele weke voor sy verskyning elke Vrydag 'n woordspeletjie (met 'n prys daaraan verbonde) in Die Burger verskyn nie, maar na die bekendstelling is 'n volbladpromosie in kleur in Die Burger, Beeld en Die Volksblad gepubliseer, met foto's van die redaksielede daarby. Hiernaas het Daniel Hugo op Radio sonder Grense (RSG) 'n onderhoud met die redakteurs uitgesaai en het Rooi Rose 'n dubbelbladartikel met 'n foto van Odendal geplaas met die titel "'n Man van baie woorde", maar met sterk klem ook op HAT self. Om die kroon op alles te plaas, is 'n geslaagde insetsel op natuurlike wyse op Sewende Laan ingewerk, met Oubaas besig met HAT in die boekwinkel.

13.2 Laastens het die uitgewers 'n los "boekie", getiteld Klein HAT, as 'n toegif los voor in elke eksemplaar geplaas wat "nuwe woorde, en toevoegings tot die vyfde uitgawe van HAT, woordspeletjies en woordraaisels" bevat.

14. Dit sou tans, ná veertig jaar, nie erg oordrewe wees om te sê: "Wat is 'n huis sonder 'n HAT?" nie.

\section{Bibliografie}

Gericke, W. 1991. Die Woordeboek van die Afrikaanse Taal — 'n Kultuurhistoriese verkenning. Ongepubliseerde M.A.-skripsie. Stellenbosch: Universiteit van Stellenbosch.

Schoonees, P.C. s.j. Die Afrikaanse Woordeboek. Johannesburg: Voortrekkerpers.

Snijman, F.J. $1975^{2}$. U woorde, u Woordeboek. Kaapstad: A.B.C. Pers. 